\title{
A objetivação de sujeitos negros amazônicos e de práticas de Marabaixo
}

\author{
The objectification of black amazon subjects and Marabaixo practices \\ Ednaldo TARTAGLIA \\ Universidade Federal do Amapá - UNIFAP \\ https://orcid.org/0000-0003-3349-242X \\ Pedro NAVARRO \\ Universidade Estadual de Maringá (UEM/CNPq) \\ https://orcid.org/0000-0003-3267-4985
}

\begin{abstract}
RESUMO: Esta pesquisa trata de visibilizar práticas discursivas que foram lançadas sobre sujeitos negros amazônicos, especialmente, aqueles praticantes do Marabaixo (ou Ciclo do Marabaixo) de Macapá-AP, que consiste em um conjunto de práticas festivas e religiosas em devoção aos santos da Igreja Católica. O trabalho centra-se nos discursos de objetivação desses sujeitos a partir de um dispositivo religioso cristão. Filia-se aos estudos discursivos foucaultianos, a partir dos quais são mobilizados os conceitos de sujeito, poder e dispositivo (FOUCAULT, 1977, 2013, 2015; DELEUZE, 1990; AGAMBEN, 2005). Selecionaram-se seis sequências discursivas de textos de jornal impresso, livro, blog e reportagem televisiva que veicularam entre os séculos XIX e XXI. O movimento descritivo-analítico sinaliza que a Igreja construiu um saber deslegitimador acerca dos negros e de suas práticas de Marabaixo, o qual se inscreveu na historicidade desses sujeitos e do corpo social do estado do Amapá.
\end{abstract}

Palavras-chave: Práticas discursivas. Objetivação. Sujeito negro amazônico. Marabaixo.

ABSTRACT: This research tries to make visible discursive practices that were launched on black Amazonian subjects, especially those practicing Marabaixo (or Marabaixo Cycle) from Macapá-AP, which consists of a set of festive and religious practices in devotion to the saints of the Catholic Church. The work focuses on the speeches of objectification of these subjects from a Christian religious device. It is affiliated with Foucault's discursive studies, from which the concepts of subject, power and device are mobilized (FOUCAULT, 1977, 2013, 2015; DELEUZE, 1990; AGAMBEN, 2005). We selected six discursive sequences of texts from the printed newspaper, book, blog and television stories that circulated between the XIX and XXI. The descriptiveanalytical movement signals that the Church built a delegitimizing knowledge about blacks and their Marabaixo practices, which was inscribed in the historicity of these subjects and the social body of the state of Amapá.

Keywords: Discursive practices. Objectification. Amazonian black subject. Marabaixo.

\section{Considerações iniciais}

Entre os séculos XVI e XIX, mais de "[...] cinco milhões de africanos foram trazidos para o Brasil na condição de escravos, não estando incluídos neste número [...] aqueles que morreram ainda em solo africano, vitimados pela violência da caça 
escravista, nem os que pereceram na travessia oceânica" (CONRAD, 1985, p. 34-43 apud PRANDI, 2000, p. 52). Assim, no decorrer de mais de três séculos, enquanto a nação brasileira se constituía, os sujeitos negros sofreram a agressividade do exercício de poder do Estado, no seu transplante do Continente Africano para o Brasil, aliado ao exercício de poder da Igreja Católica em catequizar, docilizar e apagar as práticas e os elementos referenciais desses sujeitos, além de estabelecer sua hegemonia em relação às religiões de matrizes africanas e indígenas.

Nesse contexto, as discussões empreendidas neste artigo são motivadas pela tentativa de compreender, de um ponto de vista discursivo, como ocorreu o processo de objetivação dos sujeitos negros do extremo norte da Amazônia brasileira, mais precisamente do estado do Amapá. Nosso objeto teórico de estudo recai, portanto, sobre a construção dos sujeitos negros, no contexto histórico e cultural do chamado Marabaixo, particularmente, aquele do perímetro urbano de Macapá, tendo em vista que, em virtude de tal manifestação, os negros que dela participam encontram-se inseridos em um jogo de força que funciona a partir de um dispositivo religioso cristão operado, principalmente, pela Igreja Católica.

Importa falar que o Marabaixo (conhecido também como Ciclo do Marabaixo), na atualidade, é uma das maiores tradições festivas e religiosas afro-amapaenses em devoção aos santos da Igreja Católica. Ele é um festejo religioso que congrega elementos do catolicismo e de religiões africanas. No interior do Marabaixo acontecem vários rituais com simbologias e significados próprios, que vão desde orações e cultos aos santos católicos, consumo de bebidas alcoólicas à base de gengibre ${ }^{1}$, a prática de danças ao som de tambores e o uso de vestimentas coloridas que envolvem todo esse ritual que, na sociedade brasileira católica dos séculos passados, era visto como profano.

O Ciclo possui algumas singularidades em relação ao local em que é praticado. Ele acontece em comunidades remanescentes de quilombos e nas zonas urbanas e rurais de alguns municípios amapaenses. No Marabaixo urbano de Macapá, os festejos são em devoção ao Divino Espírito Santo e à Santíssima Trindade, os quais acontecem todos os anos após a Quaresma e se estendem até o primeiro domingo após o feriado de Corpus Christi. Desse modo, o Marabaixo de Macapá se estende por aproximadamente dois meses e, por isso, recebe também o nome de Ciclo (VIDEIRA, 2010, TARTAGLIA, 2019).

\footnotetext{
${ }^{1}$ A bebida é chamada de gengibirra e é feita à base de gengibre, açúcar e aguardente. O gengibre é atribuído ao gosto de alguns orixás da cultura afro-brasileira.
} 
O Marabaixo é cultuado por sujeitos negros remanescentes de escravos e de refugiados amapaenses, entretanto é uma festa aberta a todos os que queiram participar de suas práticas ritualísticas. O Marabaixo faz com que os sujeitos negros produzam discursos e também sejam objetos de discursos.

As práticas de Marabaixo se inscrevem no e seguem o calendário católico, entretanto, ressaltamos que nem sempre houve diálogo entre a Igreja e os sujeitos praticantes do Ciclo. Outras práticas de matrizes africanas, no Brasil, se fundiram com rituais da Igreja Católica; a título de exemplo, citamos as congadas de Minas Gerais, em que os sujeitos praticantes são constituídos pela parcela pobre e negra da cidade, como em Serra do Salitre; outro exemplo são as congadas do estado de São Paulo, como em Ilhabela e Ubatuba (COSTA, 2006). Dessa maneira, as práticas e os rituais da congada também visibilizam discursos do passado que, de algum modo, atravessam o presente, em processos de objetivação de negros e de suas práticas, muitas vezes, ainda colocadas à margem da sociedade e da história.

Nesse sentido, diante de conflitos entre os que se consideram brancos e os sujeitos negros, bem como entre Igreja Católica e os rituais dos sujeitos negros, a congada conseguiu conquistar o espaço público, por se configurar como uma manifestação religiosa consentida pela sociedade; entretanto, outras práticas religiosas de origem africana, como a Umbanda e o Candomblé, foram discriminadas, e talvez ainda sofram resistência por não serem aceitas por parte da sociedade, pois são vistas como primitivas pelo corpo social e por outras religiões (MERLO, 2008).

Entre tais manifestações religiosas, nosso estudo está centrado nos discursos de objetivação dos negros, levando em consideração um conjunto de saberes e poderes maquinados pela Igreja Católica contra as práticas dos sujeitos do Ciclo. Desse modo, formulamos a seguinte interrogação: como a Igreja construiu um saber, sobre as práticas e os sujeitos praticantes de Marabaixo, que tentou deslegitimar essas festas diante do corpo social macapaense?

Em outros trabalhos (TARTAGLIA 2019, 2020), discutimos com mais fôlego acerca do dispositivo religioso cristão e visibilizamos as relações de poder e de resistência em processos de subjetivação dos sujeitos do Marabaixo, sustentados, especialmente, nos escritos de Foucault (1977, 2015a) e Deleuze (1988). Não é esta a questão tratada no presente artigo, pois, aqui, exploramos os modos de objetivação dos sujeitos e das práticas de Marabaixo, operados a partir do dispositivo religioso. 
Nesse sentido, para responder ao nosso questionamento, tomamos como base um aporte teórico-metodológico formulado a partir de uma análise de discursos de orientação foucaultiana, da qual extraímos, especialmente, os termos conceituais sujeito, poder e dispositivo (FOUCAULT, 1977, 2006, 2013, 2015a, 2015b; DELEUZE, 1990; AGAMBEN, 2005), que são mobilizados durante a análise de seis séries discursivas selecionadas de textos de jornal impresso, livro, blog e reportagem televisiva veiculados desde o século XIX até a atualidade. Esse corpus discursivo, em nosso entendimento, sinaliza os processos de objetivação dos sujeitos negros e das práticas de Marabaixo do perímetro urbano de Macapá.

\section{O sujeito e a questão do poder}

Em "A vida dos homens infames", ao analisar documentos do século XVII ao XVIII, Foucault (2006) selecionou textos de petições, cartas régias, documentos de internamento etc. com o objetivo de realizar não uma obra histórica, mas uma "antologia de existentes". Ele trabalhou com os discursos que representaram as vidas breves de sujeitos singulares, como relatou o autor, pois a vida desses sujeitos foi descrita de forma ínfima em algumas linhas ou em algumas páginas.

Nesse texto, Foucault (2006, p. 208) se propôs a “[...] reunir alguns rudimentos para uma lenda dos homens obscuros, a partir dos discursos que, na desgraça ou na raiva, eles tocam o poder". Assim, sobre o lendário ou, ainda, sobre a forma de objetivação, o autor ressaltou que "[...] se é puramente imaginário, a lenda narra sobre ele tantos relatos insistentes que ele toma a espessura histórica de alguém que teria existido", isto é, os discursos são lançados sobre os indivíduos tornando-os sujeitos (FOUCAULT, 2006, p. 208). Aquilo que foi dito sobre esses homens e mulheres remete a suas existências; em contrapartida, aquilo do que eles foram ou fizeram nada subsiste, além das poucas descrições nos textos analisados por Foucault.

Retomando a discussão para nosso recorte analítico, entendemos que há uma produção discursiva que se projetou sobre os sujeitos negros e suas práticas, o Marabaixo, desde o século XIX. Nessa produção, há o funcionamento de um jogo de forças que, em determinados momentos, pesou sobre as práticas dos negros, levando-os a uma reconfiguração do Ciclo. Desse modo, a existência do Marabaixo também é a existência dos sujeitos que se identificam com essas práticas ritualísticas. 
A partir disso, procuramos mostrar como a Igreja Católica construiu um saber acerca do negro de Macapá e de suas práticas discursivo-ritualísticas, muitas vezes discursivizados, em exercícios de poder, como profanos e imorais. Assim, esse jogo de forças referido ancora-se em determinadas escolhas linguísticas presentes nos enunciados, as quais lançam dizeres sobre os sujeitos negros, marginalizando tanto eles quanto suas práticas.

Em seus últimos escritos, Foucault (2013) evidenciou o objeto de suas pesquisas dos últimos vinte anos de trabalho. $\mathrm{O}$ autor afirmou que não estava preocupado em estudar os fenômenos do poder, muito menos em teorizar sobre o assunto. Disse que estava centrado em criar uma história que pudesse pôr em visibilidade as diferentes maneiras em que os indivíduos tornaram-se sujeitos em nossa cultura. Assim, ele destacou três modos de objetivação que tornam os seres humanos sujeitos.

O primeiro corresponde aos modos de investigação que tentam “[...] atingir o estatuto de ciência, como, por exemplo, a objetivação dos sujeitos do discurso na grammaire générale, na filosofia e na linguística". O segundo modo de objetivação estuda o sujeito em práticas divisórias, isto é, “[...] o sujeito é dividido no exterior e em relação aos outros”. Desse modo, tem-se o processo de objetivação, como exemplo, seus estudos acerca do louco e do são, do doente e do sadio etc. Já o último modo, o que corresponde ao trabalho final de Foucault, diz respeito ao "[...] modo pelo qual um ser humano torna-se ele próprio um sujeito". Como exemplo, os estudos de "História da Sexualidade", em que aborda o domínio da sexualidade, sinalizando o modo como "[...] os homens aprenderam a se reconhecer como sujeitos de 'sexualidade"' (FOUCAULT, 2013, p. 273-274).

Com isso, Foucault (2013) adverte que seu trabalho não tem como núcleo o poder, mas sim o sujeito. Nesse sentido, traçamos nosso objeto de estudo, que se configura como o sujeito negro do Marabaixo - entretanto, não é fácil conceituar e dizer quem é esse sujeito. O filósofo francês chama a atenção para as "necessidades conceituais", e isso não deve estar fundado em uma teoria do objeto. Devemos ter conhecimento das condições históricas que determinam nossa conceituação. Assim, procuramos estudar os sujeitos negros do Marabaixo sob a óptica das relações de poder entre esses sujeitos e a Igreja Católica, pois, a nosso ver, colocam em visibilidade os acontecimentos históricos e, assim, podemos ter consciência histórica da situação do presente. 
A partir disso, tratamos, neste trabalho, do segundo modo de objetivação dos sujeitos, apontado por Foucault, o qual associamos aos vários conflitos entre Igreja Católica e praticantes do Marabaixo. Desses conflitos, destacamos um que ocorreu no final da década de 1940 e ficou marcado na vida dos sujeitos negros. Estamos nos referindo ao ato da Igreja proibir as práticas de Marabaixo dentro da igreja de São José de Macapá, localizada no centro dessa cidade. Com isso, os sujeitos negros ficaram impedidos de praticar as danças e os cantos, de utilizarem as caixas (tambores) e de fazerem seus ritos dentro do estabelecimento religioso.

Esse fato passou ao nível do discurso, isto é, ao nível do acontecimento discursivo, pois se inscreveu no curso da historicidade dos sujeitos do Marabaixo. Sobre o acontecimento, Foucault (2005) afirma que há níveis de acontecimentos: uns estão visíveis e podem ser classificados como de maior amplitude, outros invisíveis e podem ter uma dimensão menor, mas não com grau inferior de importância. Em vista disso, consideramos a proibição das práticas de Marabaixo dentro da igreja de São José como um acontecimento de maior amplitude, pois, de alguma forma, afetou as vidas dos sujeitos e suas práticas.

Nesse sentido, fizemos um recorte do depoimento de um sujeito negro do Marabaixo, Martinho Ramos, filho de Mestre Julião o qual foi o líder dos negros do bairro Laguinho, por volta de 1950. Na sequência discursiva (SD) destacada, o sujeito relata o exercício de poder da Igreja Católica, oriundo do acontecimento mencionado.

SD 1:

Até 1948 tudo ia muito bem. Mas depois que os padres chegaram aqui (em Macapá) entenderam que o marabaixo era macumba, aí houve uma grande queda, mas ele (Julião) aguentou... (RAMOS, 1985 apud CANTO, 1998, p. 29, grifo do autor)

Esse acontecimento, que passou ao nível discursivo, diz respeito aos dizeres lançados pelos representantes da Igreja sobre as praticas do Marabaixo. Essas ações operaram no processo de objetivação de um saber pejorativo e preconceituoso que procurou silenciar, interditar e apagar as práticas de Marabaixo, bem como objetivou esses indivíduos. Isso reflete aquela direção apontada por Foucault (2013) como forma empírica de reagir à racionalidade do poder: usar formas de resistência, provocar antagonismo em vista dos efeitos sobre a vida.

A proibição da Igreja contra as práticas de Marabaixo, no interior da Igreja de São José de Macapá, manteve-se até 2013, quando ela voltou a permitir o Marabaixo 
dentro do espaço religioso católico. Contudo, ainda no século XXI, é possível ver resistência nos discursos dos sujeitos religiosos (ver SD 6). Na SD 1, o sujeito do enunciado relata que a Igreja tentou silenciar e aniquilar as práticas do Ciclo, objetivando-as como macumba e desclassificando parte de seus rituais. Essa objetivação inscreve as práticas dos negros do Marabaixo como profanas.

Para Foucault (2013), o processo de sujeição está relacionado às lutas antiautoritárias. Ele chama a atenção para as relações de poder que existem entre elas. $\mathrm{O}$ principal objetivo dessas lutas é uma técnica ou uma forma de poder. O filósofo afirma:

Esta forma de poder aplica-se à vida cotidiana imediata, que categoriza o indivíduo, marca-o com sua própria individualidade, liga-o à sua própria identidade, impõe-lhe uma lei de verdade, que devemos reconhecer e que os outros têm de reconhecer nele. É uma forma de poder que faz dos indivíduos sujeitos (FOUCAULT, 2013, p. 278).

Por esse ângulo, Foucault explica que existem dois sentidos para a palavra sujeito: sujeito submetido ao outro por meio do controle e da dependência, e sujeito preso à sua própria identidade, através da consciência ou do conhecimento de si. Nos dois casos, a palavra sujeito alude a uma forma de poder que subjuga e assujeita.

Na Figura 01, temos os sujeitos negros com suas vestimentas e adereços, tocando as caixas (tambores) e cantando em um barracão de Marabaixo.

Figura 01: O Marabaixo em um barracão dos festeiros

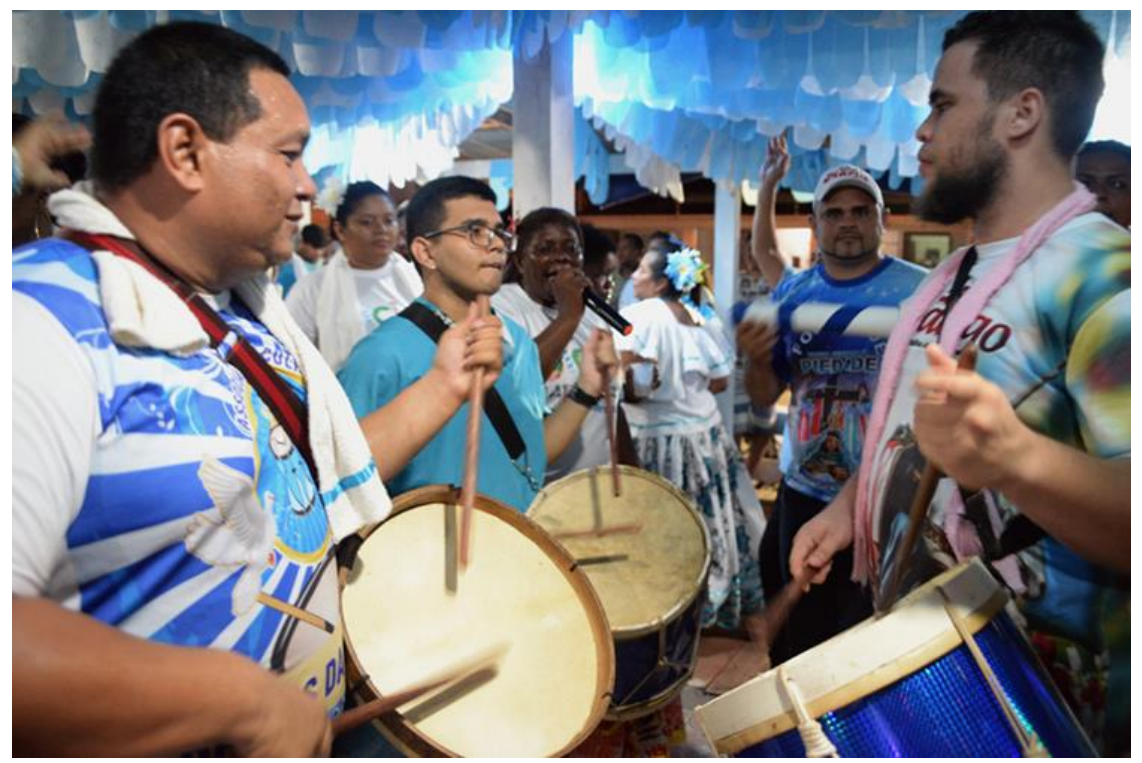

Fonte: Penha (apud CICLO..., 2019) 
$\mathrm{Na}$ sequência, trazemos um recorte de uma sequência discursiva retirada do primeiro jornal impresso de Macapá, Pinsonia, que circulou na década de 1890. A matéria de opinião é anônima, contudo expressa um discurso recorrente na época.

SD 2

Graças ao Divino-Espírito Santo, symbolo de nossa santa religião, que só exige a pratica das bôas acções, não ouviremos os silvos das víboras que dansam ao som medonho dos gritos dos maracajás, que ao mesmo tempo batem com as patas, produzindo barulho que faz arripiar as carnes, e os cabellos, que é sufficiente a provocar doudice á qualquer individuo (PINSONIA, 1898 apud CANTO, 2017) ${ }^{2}$.

Entre as várias palavras que nos chamam a atenção nesta sequência discursiva, destacamos como os negros são objetivados, bem como suas práticas discursivoritualísticas. Os negros são chamados de víboras, isto é, serpentes que, dentro de um “campo associado" (FOUCAULT, 2015b) da liturgia cristã, remetem ao pecado original cometido por Adão e Eva. A serpente foi a causa do mal, e os negros são por esse substantivo objetivados. Seus rituais são objetivados como primitivos, suas cantigas são silvos das víboras, o som dos tambores que compõem o Marabaixo é objetivado como som medonho que assusta os sujeitos civilizados.

A posição-sujeito que assume os dizeres na SD 2 recupera uma memória histórica de cunho religioso-cristão sobre a relação entre civilizado e não civilizado, religioso e profano, em que o objeto da exclusão recai sobre os sujeitos negros. Desse jogo de poder que se ancora no linguístico emerge a subjetivação de um sujeito submetido ao outro, isto é, aquilo que o negro é em relação ao seu outro (FOUCAULT, 2013). Assim, a Figura 01 visibiliza as práticas festivas, com características da cultura africana, as quais, a partir de um dispositivo religioso, fizeram, por exemplo, os dizeres das SD 01 e 02 serem enunciados contra os sujeitos e as práticas de Marabaixo. Desse modo, nessa rápida descrição analítica, percebemos que o sujeito negro do Marabaixo foi construído por dizeres que, de alguma forma, estão atravessados por relações de poder.

A esse respeito, procuramos nos escritos de Foucault uma definição para o termo poder; o que encontramos é um esclarecimento sobre essa questão, bem como a forma de investigá-la. Na realidade, ao se estudar o poder, estudamos suas relações. Nessa direção, Foucault aponta que

\footnotetext{
${ }^{2} \mathrm{O}$ texto está escrito na língua portuguesa do século XIX, assim, diverge, em alguns momentos, com a língua portuguesa moderna.
} 
O exercício do poder não é simplesmente uma relação entre "parceiros" individuais ou coletivos; é um modo de ação de alguns sobre outros. O que quer dizer, certamente, que não há algo como o "poder" ou "do poder" que existiria globalmente, maciçamente ou em estado difuso, concentrado ou distribuído: só há poder exercido por "uns" sobre os "outros"; o poder só existe em ato, mesmo que, é claro, se inscreva em um campo de possibilidade esparso que se apoia sobre estruturas permanentes (FOUCAULT, 2013, p. 287).

Na perspectiva discursiva aqui adotada, não se estuda o poder como algo que se detém, mas sim como um exercício, como um modo, para alguns, “[...] de estruturar o campo de ação possível dos outros" (FOUCAULT, 2013, p. 290). A relação de poder consiste em modos de ação de uns sobre as ações dos outros sujeitos.

A esse respeito, citamos outro dizer do sujeito Martinho Ramos, em que ele faz referência às ações da Igreja Católica que tentavam extirpar as práticas dos sujeitos negros no final da década de 1950.

\section{SD 3}

Tanto que ele [Julião] pertencia a irmandade do Sagrado Coração de Jesus e foi tirada a fita dele, então ele não pôde mais tomar parte da irmandade (RAMOS, 1985 apud CANTO, 1998, p. 29, grifo do autor).

Como já pontuamos, Julião Ramos (Mestre Julião) foi o líder do Marabaixo do Bairro Laguinho. Na SD3, é dada ênfase a uma das práticas repressoras da Igreja, que consistiu em retirar a fita da irmandade do Sagrado Coração de Jesus. A fita funciona como um elemento de credenciamento entre os fiéis e alguns ritos da Igreja Católica. Desse modo, a ação de retirar essa fita de Mestre Julião foi um exercício de poder de silenciamento operado pela Igreja, pois objetivou enfraquecer a legitimidade desse sujeito diante do grupo de negros do Marabaixo, visto que, sem tal elemento simbólico, Julião poderia ser deslegitimado pelos seus pares, resultando em um apagamento do Ciclo.

Tendo em vista que o poder se exerce e, assim, sujeitos e instituições podem operar sobre outros sujeitos ou vice-versa, compreendemos que o sujeito é ativo, pois também exerce poder. Nesse sentido, os sujeitos do Ciclo, em um exercício de poder, resistiram às práticas de silenciamento da Igreja, pois, no que diz respeito à proibição do Marabaixo dentro da Igreja de São José, eles continuaram com seus rituais pelas ruas de Macapá e construíram novos espaços, como as festas nas casas de seus membros, bem como em barracões. Além do mais, o exercício de resistência dos sujeitos negros 
também pode ser observado na SD 1: "houve uma grande queda, mas ele (Julião) aguentou...".

Isso nos leva a considerar, na esteira de Foucault, o exercício de poder como um modo de ação dos sujeitos sobre as ações dos outros, isto é, o poder classificado como "governo dos homens". O processo de objetivação do sujeito negro, a nosso ver, está relacionado ao exercício de poder da Igreja e às práticas discursivas que emergiram a partir das ações dessa Instituição. Com isso, é também objetivo destas reflexões trazer à baila as técnicas discursivas mobilizadas pela Igreja que se instauraram nas práticas sociais da comunidade local.

\section{A objetivação do sujeito e do Marabaixo a partir do funcionamento do dispositivo religioso cristão}

Nesta seção, discutimos as práticas e as ações que funcionaram a partir do dispositivo religioso cristão nos processos de objetivação dos sujeitos negros e do Marabaixo de Macapá.

Ao rever a literatura foucaultiana, encontramos uma definição para dispositivo no texto Le jeu de Michel Foucault, versão francesa de Ditos e Escritos III. Nessa versão, Foucault conceitua dispositivo como,

[...] em primeiro lugar, um conjunto decididamente heterogêneo, incluindo os discursos, instituições, arranjos arquitetônicos, decisões regulamentares, leis, medidas administrativas, enunciados científicos, propostas filosóficas, de moral, filantrópicas [...]. O próprio dispositivo é a rede que se estabelece entre esses elementos. [...] Em segundo lugar, gostaria de identificar que o dispositivo é precisamente a natureza da relação que pode existir entre esses elementos heterogêneos. [...] Em suma, entre estes elementos, discursivos ou não, há um jogo de mudanças de posição, mudanças nas funções, que também podem ser muito diferentes. [...] Em terceiro lugar, entendo por dispositivo uma espécie - digamos - de formação que, em um momento histórico dado, teve a função principal de responder a uma urgência. Por conseguinte, o dispositivo tem uma função estratégica dominante (FOUCAULT, 1977, p. 62-63).

Para Foucault, o dispositivo carrega um conjunto heterogêneo de elementos que podem ser linguísticos ou não. Trata-se da relação que se constrói a partir desses elementos, ou seja, é a rede de práticas que estão associadas a exercícios de poder. Essas relações de poder, bem com suas correlações discursivas e não discursivas, constituem a epistemologia foucaultiana de dispositivo.

Nessa perspectiva, consideramos o dispositivo religioso cristão como um conjunto de discursos verbais e não verbais, e as relações estabelecidas entre eles, como 
por exemplo, normas, leis, processos políticos etc. que envolvam exercícios de poder, práticas de categorização e de hierarquia, e que levam os sujeitos negros macapaenses a compartilharem um campo associado de práticas discursivas.

Nessa direção e com base em estudos anteriores (TARTAGLIA 2019, 2020), classificamos o dispositivo religioso cristão como práticas que envolvem elementos discursivos em nível de polarização, como as palavras céu e inferno, Deus e diabo, sagrado e profano, vida e morte, bem como outros elementos que se inscrevem nos rituais católicos e naqueles discursivizados como profanos, isto é, santos, padres, serpentes, feras, Igreja, pecado, feitiçaria, folguedo, macumba, demônios, pai de santo, barracão dos festeiros, entidades, folclore, água benta etc. Tudo isso sinaliza, a nosso ver, o funcionamento de práticas que compõem o dispositivo religioso cristão e faz operar um conjunto de ações e discursos que objetivam os negros e as práticas de Marabaixo.

Em “A arqueologia do Saber", Foucault (2015b, p. 153) ressalta que analisar uma formação discursiva é verificar um grupo de performances verbais, ao nível dos enunciados e da forma de positividade que as caracteriza “[...] ou, mais sucintamente, é definir o tipo de positividade de um discurso". Desse modo, pode ser entendido que uma formação discursiva está inserida em um conjunto de outros discursos com suas positividades.

Para Agamben (2005), Foucault teria buscado o termo positividade nos trabalhos de seu mestre, Jean Hyppolite, a respeito de Hegel. Assim, Hyppolite discutiu a oposição entre natureza e positividade. Já Hegel procurou relacionar a razão (natureza) com a história (positividade). Foucault, em seus estudos, examinou a relação entre os indivíduos e seres históricos, isto é, o indivíduo constituído em sujeito. Dito de outra forma, Foucault estudou o funcionamento dos dispositivos (ou das positividades) nas relações, nos mecanismos e nos jogos de poderes (AGAMBEN, 2005, p. 11).

Com o entendimento de positividade como dispositivo, Foucault (2015a) assevera que a maquinaria de um dispositivo é construída historicamente. Ela não se limita a discursos individuais, mas sim a práticas discursivas que se inscrevem não em uma unidade, mas em grupos, e constroem as verdades de uma época.

Isto posto, retomando a SD 1, entendemos que há uma performance verbal a qual, replicando atos da Igreja, inscreve as práticas e os rituais de Marabaixo como macumba e, como efeito do exercício de poder desse discurso, há a sinalização de "grande queda" nas práticas do Ciclo. A objetivação dessas práticas não está limitada a 
discursos individuais, mas a um conjunto de discursos que encontram uma regularidade quando tocam, especialmente, algumas práticas religiosas de sujeitos negros, como por exemplo, no Brasil, o Candomblé e a Umbanda, que foram discursivizadas como práticas profanas, insanas e irreligiosas, como também o vodu, no Haiti, que "[...] foi perseguido e marginalizado em boa parte da história haitiana" (TARTAGLIA; BURGEILE, 2017, p. 17). Esse direcionamento discursivo das práticas do Ciclo resultou em uma queda dos rituais dos sujeitos negros do Marabaixo, por corolário, faz ver o exercício de poder da Igreja em apagar as práticas desses sujeitos.

Consideremos, nesse viés teórico, mais uma sequência discursiva do Pinsonia, publicada em 1898. Trata-se de um texto de cunho jornalístico, cujos dizeres dão visibilidade ao funcionamento do dispositivo religioso que atuava na época, em relação ao sujeito negro e às práticas de Marabaixo.

SD 4

Até que afinal desapareceo o infernal folguedo, a dança diabola do Mar-Abaixo; serà uma felicidade, uma ventura, uma medida salutar aos órgãos acústicos, se tal troamento não soar mais, senão nas profundezas da terra [...] (PINSONIA, 1898 apud CANTO, 2017).

O Marabaixo, desde o século XIX, foi objetivado como aquilo que fugia da doutrina católica, por se tratar de práticas e rituais de negros (ver Figura 01). Na SD 4, essas práticas são discursivizadas como infernais e diabólicas. Nesse sentido, tem-se a reprodução de práticas discursivas lançadas pela Igreja, funcionando em um espaço jornalístico que objetiva os rituais dos negros na tentativa de afetá-los, ao mesmo tempo em que dissemina a hegemonia do catolicismo para os sujeitos leitores da época, os quais se configuravam, em uma minoria, como negros alfabetizados. Pelo exposto, a grande massa leitora era a elite branca macapaense. A SD 4 é um exemplo do conjunto arquitetônico de saberes operado em redes.

Deleuze (1990) elenca três dimensões do dispositivo destacadas por Foucault: a primeira corresponde à curva de visibilidade; a segunda diz respeito à curva de enunciação e, a última, a linha de força. A curva de visibilidade

[...] não se refere a uma luz em geral que ilumina objetos preexistentes; ela é feita de linhas de luz que formam figuras variáveis e inseparáveis deste ou daquele dispositivo. Cada dispositivo tem o seu regime de luz, a forma como esta cai, se esvai, se difunde, distribuindo o visível e o invisível, para fazer 
nascer ou desaparecer o objeto que não existe sem ela (DELEUZE, 1990, p. 155 , tradução nossa ${ }^{3}$.

As curvas de visibilidade são estruturas que se entrelaçam entre o que está no regime de visibilidade e de invisibilidade e possibilitam a existência do objeto discursivo.

No que diz respeito às curvas de enunciação, Deleuze (1990, p. 155-156, tradução nossa ${ }^{4}$ ) afirma que elas “[...] remetem a linhas de enunciação em que se distribuem as posições diferenciais dos seus elementos; e, se as curvas são elas próprias enunciações, o são porque as enunciações são curvas que distribuem variáveis [...]". Com isso, entendemos que a curva de enunciação não é somente aquilo que se diz sobre os sujeitos ou sobre as práticas de Marabaixo, mas, sim, tudo aquilo que se pode dizer e justificar acerca do universo das festividades do Ciclo e dos sujeitos negros.

O último elemento que compõe o dispositivo se define como sendo as linhas de forças. Segundo Deleuze (1990, p. 156, tradução nossa ${ }^{5}$ ), a linha de forças “[...] ocorre 'em cada relação de um ponto com outro' e passa por todos os lugares de um dispositivo. Invisível e indizível, essa linha está intimamente misturada com as outras e, ainda assim, não pode ser distinguida". Nesse sentido, se as linhas de força correspondem ao campo do poder, podemos dizer que o exercício de poder, operado a partir do dispositivo religioso, pode ser executado pelos sujeitos negros, pela Igreja Católica, pelo corpo social local etc., pois a linha de força permeia as demais dimensões do dispositivo.

Em vista disso, recortamos enunciados de uma entrevista do primeiro bispo de Macapá, D. Aristide Piróvano, para o Jornal do Povo (Macapá) de 1980:

\section{SD 5}

Disse que era muito amigo de Julião Ramos, mas folclore é folclore, religião é coisa séria e não podemos misturar as duas coisas. A Igreja não é contrária à diversão do

\footnotetext{
${ }^{3}$ La visibilidad no se refiere a una luz en general que iluminara objetos preexistentes; está hecha de líneas de luz que formam figuras variables e inseparables de este o aquel dispositivo. Casa dispositivo tiene su régimen de luz, la manera en que ésta cae, se esfuma, se difunde, al distribuir lo visible y lo invisible, al hacer nacer o desaparecer el objeto que no existe sin ella (DELEUZE, 1990, p. 155).

${ }^{4}$ Pues las enunciaciones a su vez remiten a líneas de enunciación en las que se distribuyen las posiciones diferenciales de sus elementos; y, si las curvas son ellas mismas enunciaciones, lo son porque las enunciaciones son curvas que distribuyen variables [...]. (DELEUZE, 1990, p. 155-156).

5"La línea de fuerzas se produce 'en toda relación de un punto con otro' y pasa por todos los lugares de un dispositivo. Invisible e indecible, esa línea está estrechamente mezclada con las otras y sin embargo no se la puede distinguir" (DELEUZE, 1990, p. 156).
} 
povo, mas não se pode misturar água benta com o diabo (PIRÓVANO, 1980 apud

CANTO, 1998, p. 29-30, grifos do autor).

Nesta sequência discursiva, chamamos a atenção para o campo lexical, em especial para o uso de palavras ao nível de polarização, tais como: folclore e religião, diabo e água benta, para caracterizar, de forma pejorativa, as práticas do Marabaixo, bem como delinear as práticas hegemônicas da Igreja. O Marabaixo, para o sujeito bispo, se configura como folclore e diversão dos sujeitos negros, entretanto, deve ficar distante das práticas da Igreja, consideradas como de bem.

Assim sendo, as curvas de visibilidade e de enunciação permitem que os discursos acerca dos sujeitos negros e das práticas do Marabaixo ganhem sentidos, se inscrevam em um campo associado. Tais curvas são fixadas pelo próprio dispositivo que as sustenta, não se tratando, assim, de um efeito preestabelecido, mas de uma maquinaria construída por um jogo de força.

Dando sequência às análises, o foco recai sobre um recorte de uma matéria televisiva de 2013, por meio da qual o Jornal AMAPÁ TV (filiado à Rede Globo de Televisão) registrou a retomada das práticas de Marabaixo no interior da Igreja de São José de Macapá. A SD 06 traz os dizeres do Padre Lourenço Filho:

SD 6

- Hoje é um dia que a gente está festejando, celebrando a entrada da coroa, a benção das murtas ${ }^{6}$. E a gente tem que ser uma igreja que saiba dialogar, aproveitar os elementos essenciais da cultura amapaense. A igreja não pode se impor de tal maneira, sem respeitar a tradição... as tradições do povo. E o marabaixo é uma das maiores expressões culturais que o amapaense tem. Então, de certa forma, menosprezar isso é menosprezar a história, é menosprezar o seu próprio povo, é perder a essência da sua cultura (APTV..., 2013, grifo nosso).

A permissão para a retomada do Marabaixo dentro da Igreja de São José era um ato aguardado há mais de 60 anos pelos sujeitos negros. Na SD 06, temos o único momento da reportagem em que o sujeito padre discursiviza. $\mathrm{O}$ religioso ressalta que estão comemorando e celebrando a entrada da coroa do Divino Espírito Santo e abençoando as murtas, e não uma aceitação velada acerca das práticas de Marabaixo.

Nas palavras finais do padre, está expressa a seguinte posição discursiva: “[...] de certa forma, menosprezar isso, é menosprezar a história, é menosprezar seu próprio

\footnotetext{
${ }^{6}$ A murta consiste em uma planta aromática típica na vegetação local. Nos festejos à Santíssima Trindade e ao Espírito Santo, a murta simboliza a planta entregue a Noé por uma pomba, após o período do dilúvio, de acordo com a liturgia bíblica. Essa planta também é utilizada nos enfeites e como adereços no Ciclo do Marabaixo.
} 
povo, é perder a essência da sua própria cultura", ou seja, a Igreja menosprezou as práticas dos sujeitos negros materializadas no Marabaixo, entretanto, não conseguiu eliminá-las. É claro que todos os processos de silenciamento do Ciclo foram exercícios de poder e, de certa forma, proporcionaram mudanças nas vidas dos sujeitos negros e nas formas de manifestação do Marabaixo.

A manifestação discursiva, na SD 06, retoma dizeres dos séculos XIX e XX, pois rememora as tentativas de apagamento e silenciamento das práticas dos sujeitos negros, colocando em invisibilidade o exercício de poder da Igreja Católica.

\section{Considerações finais}

No presente texto, procuramos descrever e compreender as técnicas discursivas utilizadas pela Igreja, por meio do dispositivo religioso cristão, para objetivar os sujeitos negros e as práticas de Marabaixo em Macapá. Com a análise aqui empreendida, observamos, nas SD 05 e 06, os dizeres dos sujeitos representantes da instituição Católica que ora reduzem as práticas dos sujeitos negros do Marabaixo, ora silenciam o movimento. Já, nas SD 02 e 04, encontramos os dizeres anônimos que circularam em um jornal local de 1898 e colocam em funcionamento os discursos de opressão, separação e apagamento, lançados pela Igreja e operados pelo corpo social. As SD 01 e 03 trazem a voz do sujeito negro, em meio ao exercício de poder da Igreja em apagar seus referenciais identitários.

Com isso, as redes discursivas, inscritas no dispositivo religioso cristão, colocam em funcionamento discursos que transitam pelo campo religioso, jornalístico e social, atuando no processo de marginalização dos sujeitos negros e das práticas de Marabaixo.

Por fim, compreendemos que as festividades de Marabaixo e os sujeitos negros desses rituais foram deslegitimados por ações e técnicas da Igreja Católica que se inscreveram nas práticas sociais da comunidade local. Nesse sentido, considerando as curvas de visibilidade e de enunciação do dispositivo religioso, a Igreja objetivou determinados sujeitos cujos elementos identitários e religiosos não se inscrevem na esfera reconhecida das práticas católicas e, como exercício de poder, os objetivou e classificou as suas práticas como marginais, profanas e imorais. Com isso, ela propagou a sua hegemonia em meio aos processos de apagamento e de silenciamento das subjetividades dos negros e das práticas de Marabaixo. 


\section{REFERÊNCIAS}

AGAMBEN, G. O que é um dispositivo? Tradução de Nilceia Valdati. Outra Travessia, Florianópolis, n. 5, 2. sem., p. 9-16, 2005.

APTV: cortejo da murta do Marabaixo em Macapá. AMAPÁ TV. Macapá, 29 de jul. 2013. Disponível em: https://www.youtube.com/watch?v=fdBtIT_c5qs. Acesso em: 25 mai. 2017.

CANTO, F. O Marabaixo de 1898. Blog Canto da Amazônia. Disponível em: http://fernando-canto.blogspot.com.br/2009/07/o-marabaixo-de-1898.html. Acesso em: 3 abr. 2017.

A água benta e o diabo. 2. ed. Macapá: FUNDECAP, 1998.

CICLO do Marabaixo: programação marca homenagem às mães. Governo do Amapá. Disponível em: https://www.portal.ap.gov.br/noticia/1105/ciclo-do-marabaixoprogramacao-marca-homenagem-as-maes. Acessado em 20 de mai. de 2019.

COSTA, P. T. M. As raízes da congada: a renovação do presente pelos filhos do rosário. 2006. 241f. Tese (Doutorado em Antropologia Social) - Universidade de Brasília, Programa de Pós-Graduação em Antropologia Social, Brasília, 2006.

DELEUZE, G. ¿Que és un dispositivo? In: Michel Foucault, filósofo. Barcelona: Gedisa, 1990. p. 155-161.

FISCHER, R. M. B. Trabalhar com Foucault: arqueologia de uma paixão. Belo Horizonte: Autêntica Editora, 2012.

FOUCAULT, M. "Le jeu de Michel Foucault. Entretien”. Ornicar? Bulletin périodique du champ freudien, n. 10, p. 62-93, juillet, 1977.

Retornar à História. In: Motta, M.B. (Org.). M. Foucault. Ditos \& Escritos II. Rio de Janeiro: Forense Universitária, 2005. p. 282-295.

A vida dos homens infames. In.: FOUCAULT, M. Estratégia, poder-saber. Ditos e Escritos IV. Manoel Barros da Motta (org.). 2. ed. Rio de Janeiro: Forense Universitária, 2006. p. 203-222.

O sujeito e o poder. In. DREYFUS, H. 1.; ROBINOW, P. Michel Foucault: uma trajetória filosófica: para além do estruturalismo e da hermenêutica. 2. ed. rev. Rio de Janeiro: Forense Universitária, 2013. p. 273-295.

2015a.

História da sexualidade 1: a vontade de saber. 3.ed. São Paulo: Paz e Terra,

A arqueologia do saber. Tradução de Luiz Felipe Baeta Neves. 8. ed. Rio de Janeiro: Forense Universitária, $2015 b$.

MERLO, M. Religiosidade: entre negociação e conflito Pentecostais, católicos e adeptos de religiões afro-brasileiras em Ilhabela e Ubatuba. Revista Nures, São Paulo, n. 8, p. 1-15, jan./abr. 2008.

PESQUISA - Marabaixo. Macondo Filmes. 14 de fev. 2014. Disponível em: https://www.youtube.com/watch?v=tdk93X8Qg0k\&t=202s. Acesso em: 11 ago. 2017. 
PRANDI, R. De africano a afro-brasileiro: etnia, identidade, religião. Revista USP, São Paulo, n. 46, p. 52-65, jun./ago. 2000.

TARTAGLIA, E.; BURGEILE, O. O deslocamento espacial de imigrantes haitianos: da desterritorialização à reterritorialização. Confins, Paris, n. 32, p. 1-21, 2017.

TARTAGLIA, E. Práticas de poder, de resistência e de subjetivação: os discursos dos/sobre os sujeitos negros do Ciclo do Marabaixo macapaense. Tese (Doutorado em Letras) - Universidade Estadual de Maringá, Programa de Pós-Graduação em Letras. Maringá-PR, 2019.

TARTAGLIA, E. A Igreja Católica e os sujeitos negros do Ciclo do Marabaixo: uma maquinaria discursiva operando práticas conflitantes. In. Fórum Linguístico. Florianópolis, v.17, n. 2, abr./jun., p. 4831-4843, 2020.

VIDEIRA, P. L. Batuques, folias e ladainhas [manuscrito]: a cultura do quilombo do Cria-ú em Macapá e sua educação. 2010. 262f Tese (Doutorado em Educação) Universidade Federal do Ceará, Faculdade de Educação, Programa de Pós-Graduação em Educação Brasileira. Fortaleza, 2010. 